\title{
Research on Purchasing and Supplier Management Based on Purchasing Quality Control
}

\author{
Xiao-Yuan SHI \\ Zhejiang Yuexiu Foreign Languages College Shaoxing City, Zhejiang, China \\ e-mail: sxy_008@126.com
}

\begin{abstract}
Keywords: Procurement quality control, Purchasing personnel, Supplier management, Performance evaluation.
\end{abstract}

\begin{abstract}
At present, enterprises have gradually realized the importance of modern purchasing management to improve the core competitiveness of enterprises. In order to realize the scientific and reasonable management of procurement, procurement related personnel should have economic, technology, management and other aspects of professional and technical skills, by constantly improve learning and exploration to improve their management level and business skills. Based on the quality of procurement management in supply chain environment under the new era of comprehensive and systematic analysis and study, proposed procurement quality control response of procurement personnel training, performance evaluation and audit based on the supplier, should be a reasonable choice and development, increase the assessment and management of procurement quality control.
\end{abstract}

\section{Introduction}

Procurement quality management is an important part of the procurement management, which directly affects the production department to produce qualified products, and the ultimate quality of the product is a major issue related to the survival of enterprises. Purchasing quality management is one of the contents of the procurement related personnel management. The quality of the procurement work is directly responsible for the procurement department of all personnel, their code of conduct and methods to determine the purchase price and quality of products. In addition, the procurement of goods quality inspection personnel can not be ignored, only strictly and they are just and stern to defend the quality of purchased products. Finally, the management of suppliers is also essential. The supplier is the supplier of the product, whether can choose to the high quality and low price product cannot leave the choice to the product owner. [1]

\section{Purchasing Ability Training and Performance Appraisal}

The enterprise of procurement staff employed generally need to "Virtue", "talent" and the quality of the former enterprise procurement staff on how to prevent kickbacks, take advantage of the kind of duty, as a very important condition for procurement personnel selection, procurement personnel recruitment and even rarely from non employees to consider, are preferred the old staff and their relatives play. However, with the modern supply chain environment, the importance of procurement business is becoming more and more prominent.

\section{Ability Aspect}

\section{Cost, Value Consciousness and Analyzing Ability}

The procurement cost of raw materials accounted for a large part of the total cost of the enterprise, so the procurement staff will need to firmly establish the consciousness of cost, very careful in reckoning, never spend money a wronged, can save save, do not hold indifferent attitude. Clear the importance of the procurement of corporate profits, know the leverage effect of procurement, from their own work to make more contributions to the enterprise. At the same time the procurement staff 
should have a sense of value, "a penny, one goods", only buy, not expensive, considering the purchase cost at the same time, but also consider the cost of transportation and installation cost, delivery time, the deposit and the balance of payment proportion, customer service service and a series of cost, should be has a strong capacity of value analysis.

\section{Negotiation and Presentation Skills}

The procurement staff negotiating with suppliers is an important content in the procurement, grasp the initiative and active in the negotiations will be for their subsequent put conditions smoothly and lay a good foundation. The procurement personnel both at the negotiating table debate, or the signing of the contract, should be concise and comprehensive, accurate, not to say, but also consider the situation, not only to move, not only It stands to reason., to win as much as possible for the interests of enterprises, but also have a win-win strategic consciousness.

\section{Professional Knowledge}

Each buyer must have the knowledge of their own procurement of goods. The source of raw materials, products, performance, composition, cost, attention and other aspects should have a good knowledge of reserves, so as to grasp the initiative, will not be misled or deceived by the opponent. Of course, a good procurement staff have the knowledge and ability is not only refers to these, the goods there should be some basic knowledge, marketing ability, consumer psychology knowledge, ability to improvise etc..

\section{Moral Aspect}

\section{Strong Sense of Responsibility}

The purchasing department purchasing funds, often involving tens of millions, some large enterprise funds will easily reach tens of millions or even billions of dollars, such a huge amount of money, if you are confused by the interests of suppliers, the other out of several points of the rebate will have tens of thousands or even millions of commissions, this is not exciting. So, each procurement staff to be the usual, not for the benefit of the move, have a strong sense of responsibility, responsible for enterprise, to society, to their own conscience, knowing yourself to get a little petty profits, may bring the enterprise and society have huge losses and damages, keep in mind: Forget honour at the prospect of profits!

\section{Professionalism}

Professional dedication is to engage in any work must have a good character, procurement staff is no exception. With respect of professionalism is the basic requirement for the job, the purchasing department staff professionalism is directly related to the supply of goods and materials enterprises, employees with good professionalism on the job can not only guarantee the supply and production, will also contribute to the enterprise cost savings. [2]

\section{Patience and Carefulness}

Procurement is actually a very difficult task, not only to deal with different departments within the enterprise employees, but also with suppliers and other enterprises outside the staff to deal with. In practice there are often people inside and outside the enterprise "blame" and misunderstanding, sometimes good deeds may not be recognized by others, this is the psychological and ideological will inevitably be some impact, so we need some psychological quality. Especially in some large project procurement, negotiation, and preparing for each other for a long time, this need to have enough patience to suppliers and to communicate in some aspects, can not meet the requirements of the supplier, it should be the emotional aspects of the care, sometimes some small details of human care, may be dense willow trees and bright flowers produce unexpected results. In negotiations with each other to be good at, knowing from the subtle to negotiations and seek, and thus targeted to deal with. In agreement with each other, should carefully consider every word and phrase, not only through 
legal weapons to protect their lawful rights and interests of enterprises, or to leave the handle object and to make the writing games of chance.

\section{Purchasing Personnel Training}

In order to make the purchasing department staff to be competent for their own work, excellent and efficient completion of each procurement task, the purchasing manager should organize the ability to carry out the procurement of staff training. The ability to negotiate procurement training for all staff, for the procurement of basic knowledge and quality certification (ISO9000) training by purchasing skill appraisal, employee self assessment on the development and management ability training, finally become a qualified occupation procurement staff. [3]

\section{Performance Evaluation of Purchasing Personnel}

\section{Basic Principles of Procurement Performance Evaluation}

First of all, the purchasing supervisor's performance evaluation should be continuous and coherent. It is not an accidental event. According to the time period or project regularly check whether employees reached the target requirements, at the same time, clearly let employees know they will be conscious of the assessment, usually do due diligence to improve their performance goals. Secondly, the assessment should be combined with the overall goal of the enterprise, the performance appraisal of the purchasing department will be placed in the enterprise evaluation. In addition, the procurement staff performance will be influenced by the external environment and other factors, the evaluation of staff performance should be objective, open to consider, rather than mechanically, it is often difficult to convince himself, also will lose the original meaning of performance appraisal. Finally, the evaluation criteria, the selection of standards can be compared to industry standards, can also be based on the original budget, but also can be used to assess the performance of the scale of the past.

\section{Purchasing Performance Evaluation Index}

Effective performance evaluation should have a scientific assessment indicators, so as to be comprehensive, fair and effective performance evaluation of procurement staff. In general, the procurement personnel performance appraisal indicators of quality performance, mainly from the qualified incoming material acceptance (or rejection) and the number of tested number ratio or WIP acceptance (or rejection) available quantity and ratio of the number of enterprises used to assess, if the feed rate of poor quality or reject or refuse with high ratio that is, poor quality of procurement staff performance. The number of performance indicators and the material, often in the cost of waste disposal loss index to reflect the. Followed by the cost index, the difference between the interest expense of the inventory and the normal level of interest expense. Third is the time performance index, the index in emergency procurement cost index and downtime cutting loss index, the difference between the representation and the mode of transportation during the suspension of operations personnel salary losses that reflect expedited transportation expenses incurred with normal conditions. Finally, the price performance indicators and procurement efficiency indicators.

\section{Purchasing Performance Evaluation}

In order to comprehensively evaluate the performance of the procurement staff, it is necessary to involve the departments and personnel involved in the procurement work. In general, participate in the procurement performance evaluation personnel procurement departments, which is directly responsible for the procurement staff, can deeply feel the staff daily work responsibility and ability, to complete the task, but also has the right to speak. Of course, the quality inspection department, the financial department, and the external suppliers that are relevant to the purchasing work of other enterprises also have the right to speak. Some companies also use third party management consultants and experts to participate in the performance appraisal of the employees. 


\section{Audit the Purchasing Staff}

\section{Improve Procurement Rules and Regulations}

The procurement personnel can make Injure the public interest to benefit one's private interest, to be sure, the procurement regulations that is, there is a big loophole in the management loopholes to the relevant personnel the opportunity. If the company has developed a series of perfect and strict procurement regulations and system, can largely eliminate the procurement personnel loopholes. This requires the procurement department heads and the relevant departments of the company to develop a more complete and scientific procurement system, standardize the behavior of procurement staff, procurement operations into a set of standardized procurement manual. So that each of the procurement activities are carried out in accordance with the standard procedures, not allowed to have additional optional action, if for special reasons, should also be in advance or after the timely report to the competent authorities or leaders of the reasons.[4]

\section{Do the Recruitment and Training of Purchasing Staff}

As mentioned earlier in this book, the buyer needs a man of "Virtue" and "talent". Therefore, the human resources department in the recruitment should be subject to the election of the people, at the same time of purchasing staff before and after induction of regular business and quality training, make them from the mouth to the heart, from writing to behavior, from the front to back to his mind, and fulfill their duties, do a good job.

\section{Establish the Credit Files of the Purchasing Personnel, Improve the Reward and Punishment Mechanism}

Each company in order to prevent corruption of the procurement staff, procurement irregularities have increased the penalties, so that they can not participate. But in practical applications are also very difficult to eliminate behavior of Injure the public interest to benefit one's private interest. The reason is strong temptation to rush into danger, dare sword blade. So, dereliction of duty corruption enterprises procurement personnel in front of the interests of the temptation, on the one hand to maintain a high pressure situation should also be another way to punish. For example, the establishment of credit linkage mechanism of procurement staff, each enterprise procurement related personnel in the recruitment, there must be a unit in charge of procurement of credit rating, once saw a candidate has repeatedly purchasing tainted behavior, may refuse the position of the company. But such measures will be extended to other social enterprises, the formation of social linkage mechanism, so many times and the huge amount of Injure the public interest to benefit one's private interest actors, once left the original unit will therefore no work can be found, no one is willing to employ him, completely broken the idea of corruption. In addition, enterprises should also increase the incentives for those who through their own work, toil, save the huge cost of active personnel procurement for the company business, should give more spiritual and material rewards, makes them energetic, happy job, not greed, not greed to form a good mechanism to corruption, thus completely to prevent collusion, kickbacks and supplier behavior.

\section{Strengthen Supplier Management}

\section{Supplier Selection and Development}

It is very important for enterprises to choose the right suppliers, which can not only save the cost, but also provide qualified products. The selection and development of an enterprise can be initiated from an existing supplier or can be developed by potential suppliers. Supplier selection is the first to consider the number of suppliers. Single source suppliers are generally suitable for the sole supplier of a key part of the enterprise and can provide a very valuable and excellent product, no need to consider other suppliers. In the case of a large quantity of procurement, it is easy to produce scale effect, and the enterprise has a great influence on the supplier. In the need for more reliable and 
shorter lead time, most often choose a single supplier. And the choice of suppliers is to ensure supply, and reduce the risk of dependence, avoid excessive reliance on a single supplier, in order to provide back-up source of supply, price and service better, sometimes enterprise policy requirements. Followed by the scale. The size of the supplier can not only reflect its strength and market influence, and sometimes it is a response to its quality, reputation, etc.. But it is difficult for enterprises to grasp the initiative and the right to speak through such cooperation. Finally, the location of the supplier. Domestic and geographically close suppliers have the advantage of short transportation cost and short delivery period, while multinational suppliers may be able to seek more competitive prices and quality of the procurement of goods. [5]

\section{Supplier Performance Evaluation}

Supplier performance appraisal is to evaluate and monitor the supplier through a series of cooperation and performance. Designed in order to improve the suppliers working day and again after selection. The purpose of the supplier performance evaluation is to satisfy the requirements of the enterprise in terms of the quality and quantity of the goods and services provided by the supplier. Secondly, in cooperation with the relevant suppliers, if it can not be fulfilled on schedule, the enterprise should be based on the results of inspection and measurement to measure whether the elimination of substandard suppliers. Finally, through the assessment, found that some of the shortcomings of suppliers, to help improve their operating conditions and better for their own enterprises to provide more satisfactory goods and services for their use. The principle of supplier performance evaluation generally has the principle of integrity, the principle of continuity and external factors. The index system of supplier performance evaluation includes quality index, supply index, economic index and support index. In addition to the above mentioned indicators, the enterprise in order to fully assess the supplier, in other factors such as service, support, coordination performance is often the content of the assessment. The specific communication skills, cooperative attitude, supplier management level, there is a problem facing the economy, technology, religion, cultural and natural aspects of service level and supplier timely processing of the environment.

\section{Measures to Strengthen Supplier Management}

\section{Establish Win-Win Ideas}

With the development of society and technology, the competition of enterprises has become more and more fierce. In modern society, all enterprises in the new supply chain environment, is no longer a single competition between enterprises, more is the supply chain competition among all enterprises. All of us, the situation is the enterprises must be deeply aware of the problem. Therefore, enterprises should abandon the traditional business philosophy, not only is an own profit maximization as the goal, and should take into account their cooperation with the downstream enterprises, establish a "win-win" and "win-win" new ideas. Really should be the ad: hello! I good! Hello everyone! Is really good!

\section{Information Sharing and Trust Mechanism}

The uncertainty of the market and the independence of each other, the procurement of goods between enterprises and suppliers in decision-making and information exchange is inevitable omissions and errors. So, in order to better cooperation. The two sides should strengthen information exchange and communication, to maintain the consistency and accuracy of information. The party is facing the same problems difficult to solve when processing should be established a joint team together to overcome the difficulties, benefit by mutual discussion. The two sides should form a regular exchange mechanism. Form a good atmosphere of cooperation. In the case of not involving business secrets, information sharing, mutual trust and cooperation. [6] 


\section{Establish Reward and Punishment Mechanism}

In order to prevent adverse speculation and suppliers with reputable suppliers of long-term cooperation, enterprises should establish incentive mechanism clearly with suppliers, discipline necessary for those who do not abide by the contract, the supplier commitment to comply with the hand. More to those who supply timely, good quality and reasonable price of the supplier of the necessary incentives, from the terms of payment, to extend the cooperation period of technical support, information sharing and other interested incentives to make for their own services.

\section{References}

[1] Ji Guojun, Cai Yuanyou, Purchasing Management, Xiamen University press, Xiamen, 2012.

[2] Zhao Yanli, Purchasing and Supply Management Practice, China Communications Press, Beijing, 2009.

[3] Li Hehua, Modern Purchasing and Supply Management, Shanghai University of Finance and Economics press, Shanghai, 2010.

[4] Zhou Yun, Purchasing Cost Control and Supplier Management, China Machine Press, Beijing, 2009.

[5] Zhu Lixuan, Lai Jun, Analysis on the quality requirements and training of College Teaching Equipment Purchasing Personnel, Value Engineering, 29(2013).

[6] Xu Jie, Purchasing Management , China Machine Press, Beijing, 2009. 